\title{
MASCULINITY AND ADVERTISEMENTS: THE CASE OF NEPAL TELEVISION
}

\author{
Indira Mishra, Lecturer of English \\ Tribhuvan University, Mahendra Multiple Campus, Dharan \\ mishraindira32@yahoo.com
}

\begin{abstract}
The article explores the television commercials broadcasted by the Nepal Television (NTV) that have male roles to analyze how masculinity is presented in them. In Nepal, studies of men and masculinities remain a rare compared with studies of women and femininity. It is essential to analyze the representation of masculinity to understand men's experiences, attitudes, beliefs and practices, not only to challenge men's superiority over females, but also to create gender equality. The aim of this article then is to study how a hegemonic masculinity is represented and constructed within NTV commercials.
\end{abstract}

KEYWORDS: Sex, gender, masculinity, femininity, stereotype, TV commercials

\section{INTRODUCTION}

Advertising is simply an enormous presence in the contemporary society. As such, it has effects beyond those normally considered to be the province of economic transactions of the market. It seems to affect our overall values and shape our media. This article seeks to analyze some of the advertisements broadcasted by the Nepal Television and to investigate how male gender roles are portrayed in them. Though the aim of television commercials is to inform the intended consumers about the goods and promote the sales of these products, they sell the ideology, belief and value system as well. It is essential to analyze the portrayal of men and women in them because what people hear and see on the media influences their perceptions, attitudes, and behaviors.

Researchers are of the opinion that many of the gender roles like what are appropriate behaviors for males and females are learned from television by the viewers, especially by the children which they perpetuate as they grow. Among other forms of media, television being close to home, has remained more influential for gender roles socialization. Exploring gender depictions in television commercials tells us something about gender portrayals in the larger medium. One may expect changes to have occurred in media, gender representation ever since the women's movement in the 1970s because how men and women are viewed in the society, has been changed. Now, women are more likely to be in work force that has traditionally held by men. However, the way men and women are portrayed in the media especially in Nepali television commercials have not been changed. To examine this, this article provides a case study of some of the commercials from Nepal Television (NTV). The purpose of this study is to put some of the advertisements screened on NTV under closer scrutiny and to analyze the portrayal of men in them. The focus of this article is on the spectacle of masculinity displayed in advertising - images of men in general and successful men in particular. Masculinity is often overlooked in terms of importance when it comes to research. This article is an attempt to narrow down the gap by pro- 


\section{Crossing the Border: International Journal of Interdisciplinary Studies}

viding a rare glimpse in an under researched area in the context of Nepal.

\section{SEX, GENDER AND MASCULINITY}

Sex is a matter of biology, which is determined by anatomy whereas gender, the traits like masculine and feminine attached to male and female, is a cultural construct. Gender refers to the roles and responsibilities of men and women that are created in our families, our societies and our cultures. The concept of gender also includes the expectations held about the characteristics, aptitudes and likely behaviors of both women and men (femininity and masculinity). Since gender roles and expectations are learned, gender is not biologically predetermined nor is it a fixed entity. Feminists like Toril Moi believe that patriarchy constructs certain characteristics as masculine and feminine and impose them on men and women. Moi contends "feminine and ('masculine') represent social constructs (patterns of sexuality and behavior imposed by cultural and social norms), and to reserve 'female' and 'male' for purely biological aspects of sexual" (209). So feminists like Moi disagree with the notion of pure femaleness and maleness based on binary opposition. Gender, thus, is concerned with not how males or females really are, but the way that a given culture or subculture perceives them, how they are culturally constructed.

The study of gender is important because it helps understand women's subordination to men, which is socially constructed. However, until now there is confusion between sex and gender, and gender issues are taken as female issues and are concerns of women. It may be that feminists were one of the first ones to analyze the gender representation in literature and other cultural texts and protest the misrepresentation of women in them. But, gender studies is concerned with not only the representation of women but also of men. According to Desiree Lwambo, a sociologist, gender analysis as a tool can be used to dismantle the gender inequalities and to promote alternative modes of (inter-) action (8). Studies on gender representation help to measure how society views men and women and how gender roles go on changing with the changing social process. Since gender roles are learned and go on changing, the theorists of gender studies argue that they can be unlearned as well.

Gender studies is concerned with studying the representation of both men and women in literature and other art forms. However, the representation of men and masculinity is often overlooked. The concept of masculinity as a recent phenomenon emerged as a means of rethinking feminist thought by embracing a more relational approach to masculinities and femininities. According to Susan Faludi, contemporary culture damages men as much as it does women. She notes that the traditional male provider role also bitterly hurts men who cannot find employment. The traditional concept of being a man turns men into a "bread earning robot" subject to the whims of the employment market and disconnected from quality relationships and parenthood. Both men and women, as pointed by Faludi, are ruled by commercial values that revolve around those who have the most, the best, the biggest, and the fattest. It is our media-saturated consumer culture which now has men as well as women by the throat (599-602). Both sexes have now become the victims of the culture of consumerism, appearances and glamour.

Masculinity relates to perceived notions about how men should or are expected to behave in a given setting. It is a discursive accomplishment rather than a natural fact; men too are not free to construct themselves as they wish. It is their cultural history 


\section{MASCULINITY AND ADVERTISEMENTS}

which determines the kinds of identities they can consume. It may be a performance, but it is one that often becomes habitual or routinized (Edley 195). Bertens too agrees that like femininity, masculinity is a social construct. As he asserts,

What traditionally has been called 'feminine,' then is a cultural construction, a gender role that has been naturally assigned to countless generations of women. The same hold for masculinity, with its connotations of strength, rationality, stoicism, and self reliance [....] Masculinity, too, is a cultural construction (98).

Obviously, masculinity refers to the socially constructed characteristics that society expects for the male sex.

R. W. Connell explores the historical origins of attitudes toward masculinity. $\mathrm{He}$ looks back into the sixteenth century Europe and the changing social and religious climate to trace the development on individualism. He contends that industrializations, exploration, and civil wars became activities associated with men and formed the basis for modern masculinity. He writes that masculinity is "simultaneously a place in gender relations, the practices through which men and women engage that a place in gender and the affects of these practices in bodily experiences personality and culture" (71). Masculinity is a relative term which is defined and shaped by what it cannot be feminine. Theoretically, the masculine man is free of any feminine traits, including weakness, passivity and subordination. It, for example, denies narcissism and exhibitionism and remain free of traits such as vulnerability and sensitivity which are regarded as feminine traits

If discussed in particular, masculinity is semiotically connected with, opposed to and in relation to femininity. Gender politics are changing, there have been resistance on sexist stereotypes, and there now exists a myriad of gender identities. I contend that cultural messages within the advertising discourse, nonetheless, still function largely to reinforce traditional gender roles and conservative forms of masculinity and femininity.

\section{MASCULINITY IN NTV COMMERCIALS}

One of the major functions of masculinity as suggested by Lwambo is "on the male sex role, describing ways men perform the social role of being male" (8). The idea is to focus on "... what it means to be a man - in words, flesh, deed, affect; in relation to others; in various arenas of daily social life- and the ways in which masculinity may be performed" (Chopra et al. 3). In Nepali society, strength, competence, independence, and rationality are associated with masculine qualities whereas fragility, passivity, and emotionalism are taken to be the feminine ones. Men are always associated with reason and rationality which can be demonstrated by an analysis of the advertisement made for New Lifebuoy, a bathing soap.

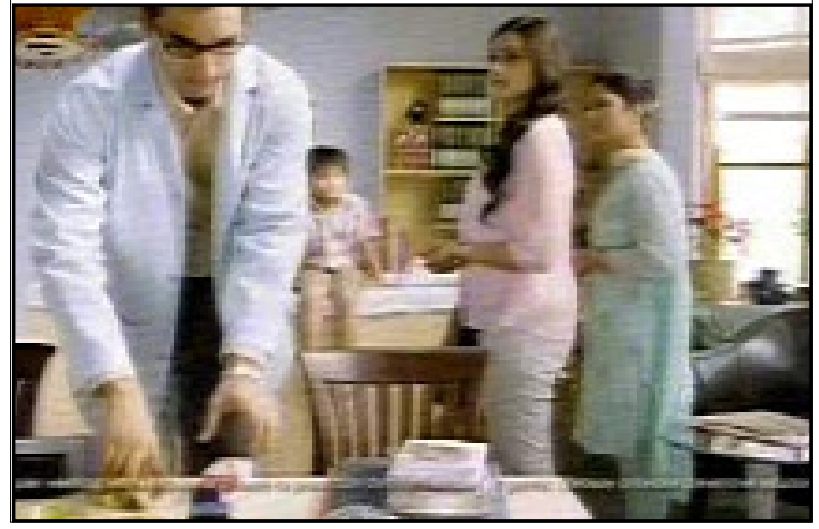

Fig. 1. New Lifebuoy Advertisement on NTV 


\section{Crossing the Border: International Journal of Interdisciplinary Studies}

In the figure 1, the setting is of a hospital clinic where a male doctor is shown in white coat. The table, the medical instruments and the layout of the room give the context. There are two young mothers standing and their young sons, whom the doctor has checked up, are on the bed. These women are anxiously looking at him and waiting for his response. Identifying the causes of their diseases, he says, "The diseases are different but the problem is caused by the same germ. If it sticks in the skin it causes skin infection, pimples, and rash; have you seen? And if it enters through hand into the mouth, causes stomach infection, flu and common cold. Either the disease is inner or outer the solution is the same." Then, he hands over each of them a cake of Lifebuoy soap. The mothers are taken aback knowing the medicinal value of the soap. They exclaim, "Lifebuoy!" The doctor assures them as "New Lifebuoy." The women are convinced by the man as he is a doctor, a certified man, who can prescribe things. It just reveals the superior status of men that both men and women have taken for granted. Here, the man stands for knowledge, command, mastery, expertise, intelligence, enlightened, professional, and so on.

This advertisement tells many things. The seriousness of the location suggests that it is a men's place. The job is certified and authentic and respectable. The women are made to stand and listen to him. The choice of scientific, medical terminologies such as "infection, rash, or flu," etc. suggests that the occupation is guided by reason and knowledge. Shulamith Firestone, one of the radical feminists, believes, we associate science and technology with men and the humanities and the arts with women. Thus, the "'masculine response' to reality is the 'technological response:' 'objective, logical, extroverted, realistic', concerned with the conscious mind (the ego), rational, mechanical, pragmatic and down-to-earth, stable" (qtd. in Tong 56). Treatment of diseases requires both knowledge and skills; it is a serious thing to do; so men's expertise is required.

Patriarchal ideology exaggerates biological differences between men and women, making certain that men always have the dominant, or masculine,roles and women always have the subordinate, or feminine ones. This ideology is so powerful, said Millett that men are usually able to secure the apparent consent of the very women they oppress. Men do this through institutions such as the academy, the church, and the family, each of which justifies and reinforces women's subordination to men, resulting in most women's internalization of a sense of inferiority to men (Tong 52). An interpretation of the advertisement made for Nepal Bank Ltd. and aired by NTV deciphers conformation of masculinity in terms of women's subordination to men.

Nepal Bank Ltd. is the sponsor of the economic news of NTV. The advertisement disseminates the message that you can be economically successful with the loan provided by the bank. It highlights the notion that material prosperity is the secret of happy family. It depicts the ideal family, a nuclear family in a comfortable house with two kids, a boy and a girl who are about to go to the school in their uniform. The feudal social mechanism governs the notion that only the riches provide happiness. The tea table, the husband taking his breakfast hurriedly in the business man like manner and the alluring wife serving him, all show the feudal tendency of the advertisement. The wife is shown in the secondary role; she is subjugated to him only as a helper. She needs to serve him because he is the upright man who has been able to accumulate the desired prosperity for the family. The triviality of the wife is reflected by the fact that she helps him put his coat, and waves her hands to the children going to school. 


\section{MASCULINITY AND ADVERTISEMENTS}

In the middle shot as shown in the figure 2, it shows a middle aged man, well groomed; his dress up shows he is about to leave for his office: a tie on his neck, wrist watch, full sleeved shirt. Then, another shot shows his alluring young wife coming from the interior to the drawing room carrying his coat;

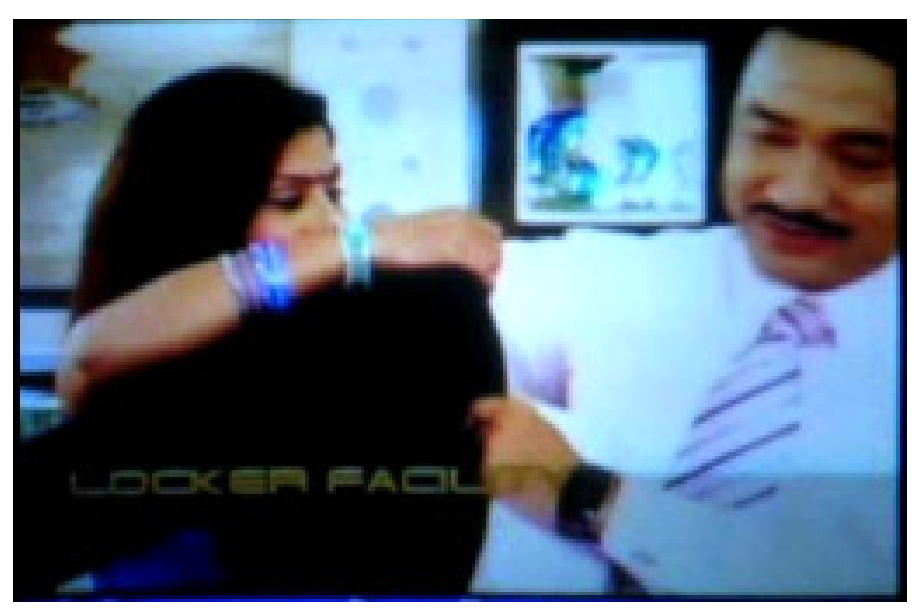

Fig. 2. Nepal Bank Ltd. Advertisement on NTV helps him wear his coat and then hands over his hand phone. The man then drives the children to the school on his way to office whereas she shakes her hand standing at the door with her cant head. Being limited to the domestic periphery, she does not cross the border of the house.

Though the advertisement is set in the modern setting; banking facility, car, mobile, the husband in his tie and the wife in the modern attire, it is not able to embrace the concept of gender equality. Moreover, the strong male voice over that supports the advertisement and the use of assertive sentences show masculine enterprise of accumulating wealth and remaining commendable: bishwa:silo sa:th hos/ sa:th hardam driDh hos/driDhata: atya: dhunik hos/ sacham hos/ tapaiko jiwanko prtek nirnyako sa:thi/

Nepal Bank Ltd. itihas bokeko atya: dhunik bank.

'Let there be faithful company. And the company will always be strong. Let the strength be ultramodern. Nepal bank limited accompanies you in your every decision for ever. It is an ultramodern bank having its history'

[English translation is mine]

The use of words like strong, strength, decision, etc. in the advertisement suggests that banking and finance are masculine fields. In addition to this, the closure in the sentences symbolizes the authenticity of the father-governed, phallogocentric language, which Julia Kristeva recognizes as the "symbolic" use of language. For her, "symbolic" is associated with the norms of social rules and regulation which the child masters slowly after he enters into the social system (239). It is, therefore, the symbolic use of language that supports male domination. The male voice-over that supports the advertisement, retaining the continuation of male domination.

The stereotypical notion as the husband is the breadwinner; he has to deal with difficulties outside and the wife should provide him emotional refuge is continued. The portrayal of family life and roles with regard to womanhood explores no other possibility than value of the traditional family model, thus, reinforcing existing societal norms and stereotypes. Furthermore, differentiation based on gender seems to be a universal feature of the human society. Men have been traditionally considered the "providers" for the family, while women have been expected to assume almost every responsibility, to take care of the child and to attend to household duties. 


\section{Crossing the Border: International Journal of Interdisciplinary Studies}

The lifestyle promoted, in this advertisement, is largely elitist in nature: the female model in the commercial is overwhelmingly extravagant; her blue dress, loose hair, makeup, pote and bangles all enhance her presence as a decorative piece. While men definitely face pressures to meet certain social ideals of masculinity; his get-up, maturity in terms of age (he looks older than his wife), and his moustache, all suggest his seriousness.

Most of the cultures view many forms of work as "women's work" or "men's work" using as basis of sexual stereotypes. For example, women are pushed into jobs like nursing, teaching, and childcare whereas men are pushed to business, science and technology and engineering. According to Jane English, terms such as 'sex roles' and 'gender traits' denote "the patterns of behavior which the two sexes are socialized, encouraged, or coerced into adopting, ranging from 'sex-appropriate' personalities to interests and professions" (qtd. in Tong 42). Boys are instructed to be masculine and girls to be feminine. Thus, to be masculine, in general, among other things, is to be rational, ambitious, and independent, and to be feminine is, among other things, to be emotional, nurturant, and dependent. So, if some biological males manifest feminine gender traits and some biological females manifest masculine gender traits such individuals will be deemed exceptional or deviant. In his research C. J. Pascoe has found that the femininity with respect to men is a matter of laughter whereas, masculinity if performed by women is cheered (6). Advertising retains theses culturally learned characteristics as natural and retains and reinforces them time and again.

Moreover, in Nepali society, the "real men" or "ideal men" are expected to be actively engaged in some good jobs, confident, courageous, responsible, respectful, helpful and so on. The chief mandate or social requirement for achieving manhood in Nepali society - for being a man - is some level of financial independence, employment or income, and starting a family. Gender role expectation demands every man to be economically independent and successful. The following analysis of the advertisement made for Nepal Life Insurance Company (NLIC) will justify this.

This advertisement features two of the most popular artists of Nepal, Hari Bamsa Acharya and Madan Krishna Shrestha in the form of colleagues who have met after a long interval. These two middle aged men are shown outside a building in a long shot. The conversation goes:

Hari Bansa: (who is in formal suit) Oh friend after such a long time!

Madan Krishna: (who is in the typical Nepali dress) Oh!

Hari Bansa: Let's go inside.

Both of them move into an office room; the Mise-en-Scene: the table, chairs, computer, and stationary; all, traditionally, suggest that it is a males' domain. The conversation takes place in the office and the talk centers on the masculine enterprise: completing higher education, going abroad, being professional, accumulating wealth and managing a settled life. The dialogue which takes place in the office room is reproduced below:

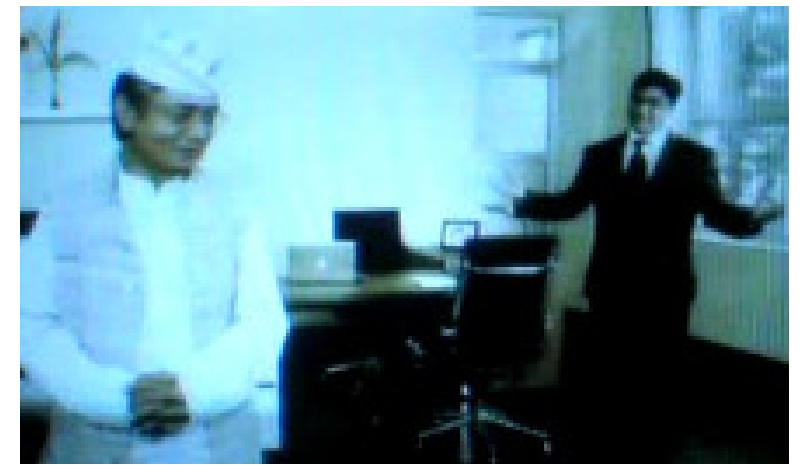

Fig. 3. NLIC Advertisement on NTV 


\title{
MASCULINITY AND ADVERTISEMENTS
}

\author{
Madan Krishna: After college you went abroad for higher education. \\ Hari Bansa: \\ You went back to serve in the village. Later I started my \\ own business. Now look at my present status.
Madan Krishna: But to study abroad, start one's own business and then get
settled, money?
Hari Bansa: $\quad$ From NLIC friend, from NLIC.
Madan Krishna: NLIC Life Insurance? I will go to the village and remind everyone about it. [English translation is mine]

Finally, it is supported by a strong male voice-over "Life Insurance for everyone's life insurance" [English translation is mine].

They are the men of reason and reality. As free men they express their individuality freely. Males are thought to be transparent, as Hari Bansa, in this advertisement, shares the secret of his economic affluence. Both of them are independent and know what they are going to do. What matters for men: education, business and settlement, for all these they need money. Making money is a masculine enterprise. To be a successful masculine man one needs to be economically settled among other things. The choice of words: foreign, education, business, settlement all have connotation with masculinity. Their getups also suggest the seriousness, commitment and responsibility demanded by the financial sector. They are well groomed middle aged men (above fifty). No suggestion of erotic desire is made by their body or dress-up. Their figures do not matter, what matters is their economic independence. Looking at their appearance one can infer many things about them: their social class, professional status and their belief system. The advertisement attempts to construct the "hegemonic masculinity" as the study of "hegemonic masculinity aims normally at identification of those sorts of men who enjoy power and wealth" (MacKinnon 8). The westernized dress up of the popular actor, Hari Bamnsa, the layout of his office, the spread arms and his confidence suggest that he is a successful man. His assertive voice also suggests his success. Since, advertisements are in a recorded form and while recording the voice of men is often sought to be bold and authoritative, men who do not have authoritative and assertive voice are not regarded as masculine. In the same way, those men who are unable to acquire knowledge, accumulate wealth and get settled in their life are excluded from its premise. Further, the absence of female participant suggests symbolic annihilation of women from the world of finance. Accumulation of wealth through commercial enterprises and gaining knowledge are men's concerns. Nepali TV commercials also focus on these aspects of masculinity and portray men with these traits.

Similarly, heroism and health is related to masculinity. And "action men" and fathers are the figures of authority. Human physical strength has always been associated with masculinity whereas fragility and vulnerability go with femininity; and such discourses construct the gender truth about men and women. An analysis of the campaign made for Jagadamba Cement, as a support to the status quo, will suffice this.

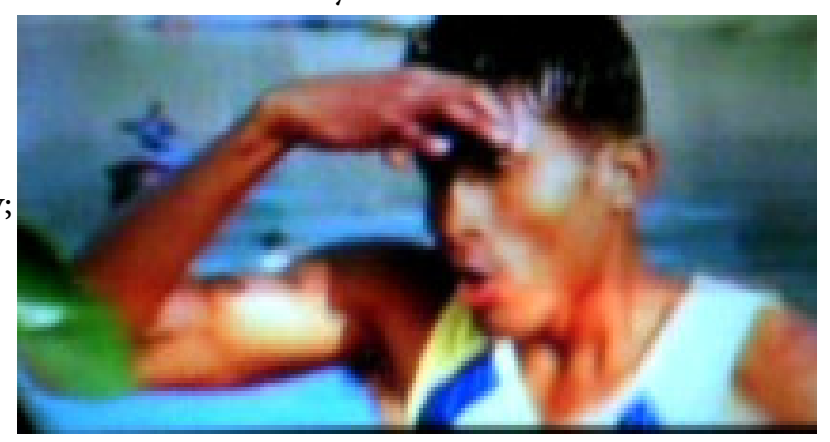

Fig. 4. Jagadamba Cement Advertisement on NTV 


\section{Crossing the Border: International Journal of Interdisciplinary Studies}

The man in this commercial is young (the figure 4), athletic - if not professional athletes - muscular, strong and confident. The commercial makes and exploits the association of the strength of the product with the strength of the man. Since man has to overcome obstacles and difficulties, the advertisement is set in outdoor, in natural wilderness location. It is the ideological implications of this representational equivalence of men/masculinity with strength and power. The outside setting as suggested by James Roberson "may in one sense be read as simple variations as the male-equals outside/female-equals inside assumption of the dominant gender ideology. Male strength is expressed in settings outside, away from the home, whether at work or not" (377). The muscular young man is shown as sweating as he strains to overcome obstacles to complete his race but it should not be confused with the sweating of a laborer whose condition is also difficult but differently difficult, dangerous and dirty. So here being a man is associated with leisure activities/sports but not only for the sake of pleasure but also to prove oneself.

Here, masculinity is constructed as a hardworking person with strong muscles. The sweat is the result of physical labor in outdoor activities. The participant is a strong, masculine man who is invincible and is able to cope with the adverse situation, the extreme weather: wild wind, hot sun and the pouring rain. He is a determined man in his Herculean attempts. His revealed body is neither for seduction nor for pleasure for the opposite sex. Rather it is to enhance that to carry out the rough and tough outdoor activities one should have strong muscles. This shows his bravery, courage and faithfulness. The participant is the embodiment of ideal masculinity; he is fearless, athletic and confident. The association and the representation focus here is on bodily strength and stamina and the struggle and skill to overcome obstacles; the focus is on real man and manly acts.

The strong male voice-over that supports the advertisement further conforms the connotation of man's strength with masculinity and its association to the strength of cement, an ingredient for construction, like buildings, bridges, pillars etc. these things are exposed to the extremities of weather and protect the human being form the hardship of nature and so is the macho man:

a:stha: ch ani bhrosa ch/ sbaiko biswas eutai ka:dhma: ch ga:m, pa:ni, a:dhi, weri chin kasiko Dar/ na zhukch yo na ruktch yo cta:n sari ubhi rhnch yo/ Nepalko srwa:dhk biswa:silo Jagadama: cement ho.

'There is faith and expectation. Everyone's confidence rests upon one's shoulder; there is no fear of sun, rain and storm. Neither it succumbs nor surrenders, rather keeps on standing like a rock. The most trusted cement of Nepal is Jagadamba Cement, Nepali’s Cement.' [English translation is mine]

The choice of words: sun, storm, rock, trust, shoulder etc. suggests masculine activities associated with building and construction. This type of work demands strength and labor. French feminists argue that male dominates women through language. The authorial voice, the focused attention and the strong muscle of the participant appropriates hegemonic masculinity. The person has a strong determination and commitment to the task which he is going to accomplish.

The scientific and technological invention has also played a vital role for the production of hegemonic masculinity. Now, masculinity is associated with expertise and technical skills (Connell 246). The association of male's muscle and masculinity with building and construction, which requires technical skills can further be revealed by an analysis of an advertisement made for Jagadamba Steel. Taken in a long shot the 


\section{MASCULINITY AND ADVERTISEMENTS}

exposition is a huge panoramic scene of a construction site. It is a tough outdoor task which requires physical strength and some sort of skill and special knowledge. Here, one has to carry loads, bear physical risk as the work is hazardous; hence the traditional concept of masculinity is juxtaposed with the product, rod that is needed for erecting the pillar and supporting the infrastructure. The strong male voice voiced by the popular model/actor Rajesh Hamal enhances the product's association with men.

Featuring the popular actor, it tries to exploit the reliability of the actor for the sale of the rod. His solid feature and long career supports the durability of the steel. To carry and handle the steel and erect the pillars, male's strong muscle is required. It also promotes a particular muscular body: tall, well built, sharp nose, wide eyes and strong assertive voice.

All the males are not like that, nor do they who work in the construction site bear supple strong physique. The men

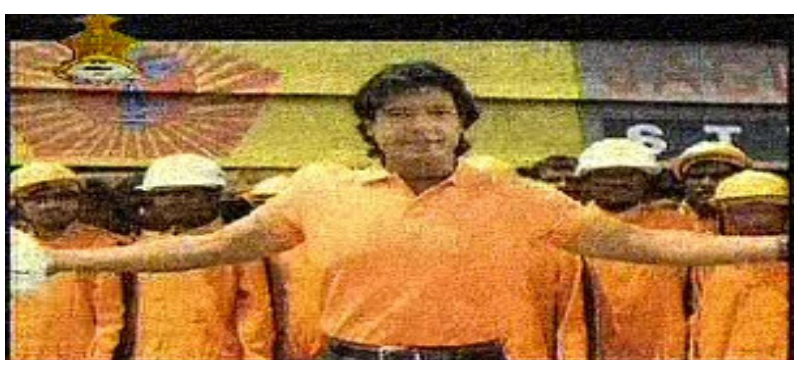

Fig. 5. Jagadamba Steel Advertisement on NTV who are lean and thin and of short height are excluded from the craft of engineering related with the steel. Besides the absence of women in the advertisement annihilates women symbolically from the engineering field. When the model/actor expands his arms, his muscles get swelled. Man's muscular and tough shoulder is the symbol of power. The point to note here is the actor's arms as the symbol of power do not represent the arms of those of the laborers. They do not have the power to assert neither their voice is authentic, so they are in the background; unidentified and they wear the helmet to safeguard their head but the actor does not. Clearly, his voice is the voice of the manufacturer/ producer, who has the power to assert. His assertion of the quality of the rod is logical and reasonable as he explains the benefit of the rod because of its homogeneity in terms of length and breadth. Further, the emphasis is on the economic aspect of the steel because of its good quality, economically one has to pay less. The male voice-over supports the advertisement, calculates its pros and cons, and provides reasonable conclusion. The mathematical calculation reveals the utility aspect of the rod. There is no hint about aesthetic pleasure/ principle. Finally, "the right price, right weight and strong construction" go together with the hegemonic masculinity that it features. Hence, as suggested by the TV commercials, building and construction are exclusively masculine enterprises as they are the things that provide support and protection.

\section{CONCLUSION}

To sum up, the male models are shown completely determined and concentrated in their task full of risk. The way they are portrayed associates them with the state of being industrious, painstaking, enthusiastic, strenuous, bold, vigorous, invincible and so on. The male characters are shown in movement and the association is with dynamism and development. These advertisements associate male with masculinity and portray men performing traditional masculine roles. Men are portrayed as free individuals guided by definite targets. They are in pursuit of knowledge and wealth.

With the advancement of science and technology, men have become more powerful to control the nature. Now, knowledge is power and to run the machine, 


\section{Crossing the Border: International Journal of Interdisciplinary Studies}

one needs the technical knowledge. That is why, these advertisements largely portray men who are either muscular man with strong muscle, an invincible one who is not defeated by the adversity of nature or the one with knowledge and expertise. By juxtaposing men with building and construction, banking and finance and other productive works, the suggestion made by the commercials is men are physically and mentally fit for such works. So the representations still reflect, reconstruct and largely reconfirm existing stereotypes. These advertisements have been unable to exhibit a shift in the nature of male role portrayal. Men in these roles still continue to play the dominating and authoritative roles; therefore, monolithic portrayals hide diversity among males.

\section{WORKS CITED}

Bertens, Hans. Literary Theory: The Basics. London and New York: Routledge, 2003. Print.

Connell, R.W. Masculinities. Cambridge: Polity Press, 2002. Print.

Chopra, Radhika, Caroline Osella \& Filippo Osella, eds. South Asian Masculinities: Context of Change, Sites of Continuity. New Delhi: Women Unlimited, 2004. Print.

Edley, Nigel. "Analyzing Masculinity: Interpretive Repertoires, Ideological and Subject Positions." Discourse as Data: A Guide for Analysis. Eds. Margaret Wetherell, Stephanie Taylor, and Simeon J. Yates. London: Sage Publications, 2001. 189-228. Print.

Faludi, Susan. Stiffed: The Betrayal of the American Man. London: Chatto and Windus, 1999. Print.

Kristeva, Julia. "The Speaking Subject." The Theory of Criticism: From Plato to the Present. Ed. Raman Selden. London and New York: Longman,1988. 238-41. Print.

Lwambo, Desiree. Men and Masculinities in Eastern DR Congo. Africa: HEAL, 2011. Print.

MacKinnon, Kenneth. Representing Men: Maleness and Masculinity in Media. New York: Oxford University Press, 2003. Print.

Men and Masculinities. 2010. Web. June 252013.

Moi, Toril. Modern Literary Theory: A Comparative Introduction. 2nd ed. Eds. Ann Jefferson and David Robey. London: B.T. Bastford, 1982. Print.

Pascoe, C.J. Dude, You're a Fag: Masculinity and Sexuality in High School. Berkeley: University of California Press, 2007. Print.

Roberson, J.E. and N. Suzuki, eds., Men and Masculinities in Contemporary Japan: Dislocating the Salaryman doxa. London: Routledge Curzon, 2003. Print.

Tong, Rosemary. Feminist Thought: A Comprehensive Introduction. San Francisco: Westview Press, 1989. Print. 